\title{
Thyroid substitution may be a risk factor for Covid-19
}

\author{
Astrid Bacle ${ }^{1}{ }^{1} \cdot$ Yannick Malledant $^{2} \cdot$ Marion Mercerolle $^{3} \cdot$ Charlotte Pronier $^{1} \cdot$ Nicolas Nesseler $^{4,5}$. \\ Camille Barbazan ${ }^{3} \cdot$ Ronan Garlantezec ${ }^{1}$
}

Received: 27 April 2021 / Accepted: 4 June 2021 / Published online: 1 July 2021

(C) The Author(s), under exclusive licence to Springer Science+Business Media, LLC, part of Springer Nature 2021

The severe acute respiratory syndrome coronavirus-2 (SARS-CoV-2) that causes coronavirus disease 2019 (COVID-19) uses angiotensin-converting enzyme 2 (ACE2) and type II transmembrane serine protease (TMPRSS2) as a gateway to enter the cells [1,2]. Although host target cells with ACE2 and TMPRSS2 on their surface are particularly present in the lung, these two proteins are also highly expressed in the thyroid [3]. Moreover, viral absorption involving the integrin $\alpha v \beta 3$ appears to be determined by thyroid hormone T4 levels (like the one in hormone replacement therapy (HRT)) [4]. Therefore, we aimed to investigate the relationship between patients under HRT and the occurrence of COVID-19.

We carried out a case-control study that included all adults patients $(n=180)$ with confirmed SARS-CoV-2 RT-PCR admitted in the University Hospital of Rennes between 16th March and 1st May 2020. For each case, two controls $(n=360)$ admitted 1 year before the cases were randomly matched (frequency matching) by age (10 years classes) and sex. All data were collected in accordance with the French legislation. For all patients included, information on body mass index (BMI) and thyroid medication at the hospital entrance were

Astrid Bacle

astrid.bacle@chu-rennes.fr

1 Univ Rennes, CHU Rennes, Inserm, EHESP, Irset (Institut de Recherche en Santé, Environnement et Travail)—UMR_S 1085, F-35000 Rennes, France

2 Surgical Intensive Care Unit, Hôpital Pontchaillou, and NuMeCan U-1241 Inserm, Université de Rennes 1, Rennes, France

3 Pôle Pharmacie, Service Hospitalo-Universitaire de Pharmacie, CHU de Rennes, 35033 Rennes, France

4 Department of Anesthesia and Critical Care, Pontchaillou, University Hospital of Rennes, Rennes, France

5 Univ Rennes, CHU de Rennes, Inra, Inserm, Institut NUMECAN -UMR_A 1341, UMR_S 1241, CIC 1414 (Centre d'Investigation Clinique de Rennes), F-35000 Rennes, France collected using electronic medical files (Dxcare ${ }^{\bullet}$ Medasys ${ }^{\oplus}$ ). We used a logistic regression to study the risk of SARS-CoV-2 in relation with HRT, with a priori adjustment on age, sex, and BMI. Results are presented as odds ratios (OR) with their $95 \%$ confidence intervals. A $p$ value $<0.05$ is considered as significant. Analyses were conducted with SAS 9.4.

A total of 540 patients were included in this study and the results are shown in the Table 1. Mean age in the COVID-19 and control groups were $62.6( \pm 17.3)$ and $62.5( \pm 17.5)$, respectively. A male preponderance was observed both in the COVID-19 group (58.9\%) and the control group (59.4\%). BMI in the COVID-19 and control group were $28.3( \pm 5.48)$ and $25.7( \pm 5.4)$, respectively. Regarding hypothyroidism etiology, the majority of patients had chronic autoimmune thyroiditis $(65 \%$ in the COVID-19 group and $60.9 \%$ for the control group), followed by hypothyroidism secondary to thyroidectomy (30\% in the COVID-19 group and $34.7 \%$ in the control group), and amiodarone-induced hypothyroidism (5\% in the COVID-19 group and $4.3 \%$ in the control group). The number of patients treated with HRT was significantly higher in the COVID-19 group than in the control group: $11.1 \%$ vs. $6.3 \%$, respectively $(\mathrm{OR}=2.60[1.26-5.38]$ $(p=0.01))$.

Our results suggest that patients undergoing HRT may be at a higher risk for COVID-19. The presence of ACE2 and TMPRSS2 at high levels in thyroid and the specific role of integrin $\alpha v \beta 3$ in SARS-CoV-2 entrance may explain this association [5]. Accordingly, T4 has been shown to modulate the affinity of integrin for other proteins, and may support cellular virus internalization [4]. Moreover, T4 regulates the expression of a panel of cytokine genes, some of which are components of the "cytokine storm" of viral infections [4]. There is also an intimate relationship between levels of $\mathrm{T} 3$ and proinflammatory activities [6]. Explanation for the results observed in our study may be consequently the hormonal status or the effect of exogenous T4 supplementation since 
Table 1 Baseline characteristics of COVID-19 patients $(n=180)$ and matched controls $(n=360)$ and results of the multivariate logistic regression

\begin{tabular}{lcclc}
\hline & $\begin{array}{l}\text { Covid-19 patients } \\
(n=180)\end{array}$ & $\begin{array}{l}\text { Controls } \\
(n=360)\end{array}$ & OR [IC 95\%] & $p$ value \\
\hline $\begin{array}{l}\text { Age, means }( \pm \text { Sd) } \\
\text { Sex }\end{array}$ & $62.6( \pm 17.3)$ & $62.5( \pm 17.5)$ & $1.00[0.99-1.01]$ & 0.90 \\
$\quad$ Female & $74(41.1 \%)$ & $146(40.6 \%)$ & Ref \\
$\quad$ Male & $106(58.9 \%)$ & $214(59.4 \%)$ & $1.02[0.66-1.57]$ & 0.92 \\
Body mass index $(\mathrm{BMI})$ means $( \pm \mathrm{Sd})$ & $28.3( \pm 5.48)$ & $25.7( \pm 5.4)$ & $1.09[1.05-1.13]$ & 0.001 \\
Thyroid hormones & & & & \\
$\quad$ No & $160(88.9 \%)$ & $337(93.6 \%)$ & Ref & \\
$\quad$ Yes & $20(11.1 \%)$ & $23(6.4 \%)$ & $2.60[1.26-5.38]$ & 0.01 \\
\hline
\end{tabular}

unfortunately no hormonal status was available in our data base.

Moreover, a recent study reported a significant reduction in T4 and TSH during the hospitalization of COVID-19 patients who had no thyroid disorder on admission [7]; these imbalances returning to normal after recovery. These findings support that patients under HRT are at higher risk of thyroid imbalances. In accordance with Speer and Somogyi prospective clinical studies might be interesting in order to analyze the thyroid function as a predictive factor for SARS-CoV-2 development and progression to respiratory failure [8]. Although our results need to be replicated with FT3, FT3/FT4, and TSH concentrations measurement, they deserve special attention for the patients under HRT during the current COVID-19 disease pandemic as suggested by Lui et al. [9].

More importantly, as many countries in the world are still facing a wave of the pandemic, it might be relevant to consider thyroid patients as a priority group in vaccination campaigns.

Acknowledgements We would like to thank Paul Deniel for his assistance with the data collection, Hélène Gilardi for her sound advice, Brendan Le Dare for his critical comments, and Maxime de Kouchkovsky for assistance in English editing.

Author contributions $\mathrm{AB}$ conceived the study. All authors analyzed the data. RG provided methodological input and contributed to the figures. All authors analyzed and interpreted the results. AB wrote the first draft of the article and all authors critically commented on and contributed to subsequent revisions. All authors contributed to and approved the final version.

Funding This research did not receive any specific grant from any funding agency in the public, commercial or not-for-profit sector.

\section{Compliance with ethical standards}

Conflict of interest The authors declare no competing interests.
Ethical approval Our institution's ethics committee approved (Opinion no. 20.147).

Publisher's note Springer Nature remains neutral with regard to jurisdictional claims in published maps and institutional affiliations.

\section{References}

1. C.G.K. Ziegler, S.J. Allon, S.K. Nyquist, I.M. Mbano, V.N. Miao, C.N. Tzouanas, Y. Cao, A.S. Yousif, J. Bals, B.M. Hauser, J. Feldman, C. Muus, M.H. Wadsworth, S.W. Kazer, T.K. Hughes, B. Doran, G.J. Gatter, M. Vukovic, F. Taliaferro, B.E. Mead, Z. Guo, J.P. Wang, D. Gras, M. Plaisant, M. Ansari, I. Angelidis, H. Adler, J.M.S. Sucre, C.J. Taylor, B. Lin, A. Waghray, V. Mitsialis, D.F. Dwyer, K.M. Buchheit, J.A. Boyce, N.A. Barrett, T.M. Laidlaw, S.L. Carroll, L. Colonna, V. Tkachev, C.W. Peterson, A. $\mathrm{Yu}$, H.B. Zheng, H.P. Gideon, C.G. Winchell, P.L. Lin, C.D. Bingle, S.B. Snapper, J.A. Kropski, F.J. Theis, H.B. Schiller, L.-E. Zaragosi, P. Barbry, A. Leslie, H.-P. Kiem, J.L. Flynn, S.M. Fortune, B. Berger, R.W. Finberg, L.S. Kean, M. Garber, A.G. Schmidt, D. Lingwood, A.K. Shalek, J. Ordovas-Montanes, HCA Lung Biological Network. Electronic address: lung-network@humancellatlas.org, and HCA Lung Biological Network, Cell 181, 1016 (2020)

2. S. Lukassen, R.L. Chua, T. Trefzer, N.C. Kahn, M.A. Schneider, T. Muley, H. Winter, M. Meister, C. Veith, A.W. Boots, B.P. Hennig, M. Kreuter, C. Conrad, R. Eils, EMBO J. 39, e105114 (2020)

3. E. Lazartigues, M.M.F. Qadir, F. Mauvais-Jarvis, Endocrinology 161, 9 (2020)

4. P.J. Davis, H.-Y. Lin, A. Hercbergs, K.A. Keating, S.A. Mousa, Endocr. Res. 45, 210 (2020)

5. C.J. Sigrist, A. Bridge, P. Le Mercier, Antivir. Res. 177, 104759 (2020)

6. P. De Vito, S. Incerpi, J.Z. Pedersen, P. Luly, F.B. Davis, P.J. Davis, Thyroid 21, 879 (2011)

7. B. Khoo, T. Tan, S.A. Clarke, E.G. Mills, B. Patel, M. Modi, M. Phylactou, P.C. Eng, L. Thurston, E.C. Alexander, K. Meeran, A. N. Comninos, A. Abbara, W.S. Dhillo, J. Clin. Endocrinol. Metab. 106, e803 (2021)

8. G. Speer, P. Somogyi, Endocr. J. 68, 129 (2021)

9. D.T.W. Lui, C.H. Lee, W.S. Chow, A.C.H. Lee, A.R. Tam, C.H.Y. Fong, C.Y. Law, E.K.H. Leung, K.K.W. To, K.C.B. Tan, Y.C. Woo, C.W. Lam, I.F.N. Hung, K.S.L. Lam, J. Clin. Endocrinol. Metab. 106, e926 (2021) 